\title{
A Systematic Review of EMG Applications for the Characterization of Forearm and Hand Muscle Activity during Activities of Daily Living: Results, Challenges, and Open Issues
}

\author{
Néstor J. Jarque-Bou *(D), Joaquín L. Sancho-Bru (D) and Margarita Vergara (D) \\ Department of Mechanical Engineering and Construction, Universitat Jaume I, E12071 Castellón, Spain; \\ sancho@uji.es (J.L.S.-B.); vergara@uji.es (M.V.) \\ * Correspondence: jarque@uji.es; Tel.: +34-964-728-125
}

check for

updates

Citation: Jarque-Bou, N.J.; Sancho-Bru, J.L.; Vergara, M. A Systematic Review of EMG Applications for the Characterization of Forearm and Hand Muscle Activity during Activities of Daily Living: Results, Challenges, and Open Issues. Sensors 2021, 21, 3035. https:// doi.org/10.3390/s21093035

Academic Editor: Ernest

N. Kamavuako

Received: 1 April 2021

Accepted: 24 April 2021

Published: 26 April 2021

Publisher's Note: MDPI stays neutral with regard to jurisdictional claims in published maps and institutional affiliations.

Copyright: (c) 2021 by the authors. Licensee MDPI, Basel, Switzerland. This article is an open access article distributed under the terms and conditions of the Creative Commons Attribution (CC BY) license (https:/ / creativecommons.org/licenses/by/ $4.0 /)$.

\begin{abstract}
The role of the hand is crucial for the performance of activities of daily living, thereby ensuring a full and autonomous life. Its motion is controlled by a complex musculoskeletal system of approximately 38 muscles. Therefore, measuring and interpreting the muscle activation signals that drive hand motion is of great importance in many scientific domains, such as neuroscience, rehabilitation, physiotherapy, robotics, prosthetics, and biomechanics. Electromyography (EMG) can be used to carry out the neuromuscular characterization, but it is cumbersome because of the complexity of the musculoskeletal system of the forearm and hand. This paper reviews the main studies in which EMG has been applied to characterize the muscle activity of the forearm and hand during activities of daily living, with special attention to muscle synergies, which are thought to be used by the nervous system to simplify the control of the numerous muscles by actuating them in task-relevant subgroups. The state of the art of the current results are presented, which may help to guide and foster progress in many scientific domains. Furthermore, the most important challenges and open issues are identified in order to achieve a better understanding of human hand behavior, improve rehabilitation protocols, more intuitive control of prostheses, and more realistic biomechanical models.
\end{abstract}

Keywords: ADL; EMG; forearm muscles; muscles role; synergies; muscle coordination

\section{Introduction}

The ability to carry out activities of daily living (ADL) is critical to ensure a full and autonomous life [1], and has been established by the WHO as the main factor for classifying the degree of disability [2]. ADLs refers to those elementary tasks that allow anyone to function with minimal autonomy and independence, including any daily activity that we perform for self-care, work, housework, and leisure. The ability of the hands to grasp and manipulate is fundamental in the performance of ADL [3] but also for working life [4]. This ability is achieved thanks to a complex musculoskeletal system, with 25 degrees of freedom that are controlled by approximately 38 muscles located in the forearm and hand [5]. These muscles can be divided into two groups: extrinsic and intrinsic muscles. The extrinsic muscles are located in the anterior and posterior compartments of the forearm whereas intrinsic muscles are located within the hand itself. Broadly, the extrinsic muscles are considered to control crude movements of the hand and produce forceful grip, while the intrinsic muscles would be responsible for the fine motor functions of the hand [6-8]. However, both the specific role of the different muscles in ADL and how the Central Nervous System dares with this redundant and complex muscular system are still unknown [9]. This information is essential for determining the impact on functionality when a given muscle is compromised because of an accident or pathology.

The measurement and interpretation of the hand kinematics and the associated muscle activation signals is complex but of great importance to deepen the knowledge of the role 
of the muscles in ADL [8]. This knowledge is not only important to rate disability but also to improve rehabilitation processes $[10,11]$ or to help in decision-making during surgical planning, among others [12]. Another important field of application is in the control of hand prostheses [13-16]. Myoelectric hand prostheses use the electrical action potential of the residual muscles in the limb emitted during muscular contractions. These emissions are measured on the skin surface, picked up by electrodes, and are amplified to be used as control signals for the functional elements of the prosthesis. Therefore, deepening the knowledge of the role of the forearm muscles in ADL may help in the selection of the muscles to control this type of prostheses.

Electromyography (EMG) emerged as a diagnostic procedure to assess the health of Muscles and the nerve cells that control them (motor neurons). The electrodes receive the electrical signals transmitted by the motor neurons that cause muscle contraction. However, these EMG signals acquired from muscles require advanced methods for their detection, decomposition, processing, and classification [17-19] that a specialist interprets. There are two basic types of electrodes to acquire these signals: surface and intramuscular electrodes. Surface electrodes are placed on the skin directly over the muscles, recording the signal from all the fibers under the two electrodes. Intramuscular electrodes can be indwelling (also known as needle) or fine wire electrodes (Fw-EMG), and they are inserted through the skin directly into the muscle [20], thus recording the signals from only few fibers. The general advantage of surface electrodes is that they are non-invasive and easy to apply. Their use, however, is limited to superficial muscles that are large enough to support electrode mounting on the skin surface, and crosstalk is particularly problematic for smaller muscles within a complex mechanical arrangement, such as the forearm [21]. Indwelling electrodes need significantly more training for their proficient use in comparison to surface electrodes. Although they are ideal for recording the activity of deep muscles, correct placement requires a detailed knowledge of musculoskeletal anatomy. Furthermore, the invasiveness of inserting a needle into the muscles, as well as the associated pain, is the major disadvantage of intramuscular electrodes [20].

EMG has been incorporated as a diagnostic technique for the detection of pathologies that affect nervous and muscular structures, and for the spatial location of the origin of the injury. Examination with needle EMG allows motor unit action potentials (MUAPs) to be evaluated. High density EMG grids allow also the identification of the MUAPs, but only for those motor units whose innervation zone was close to the surface of the muscle [22]. The morphology (duration, amplitude, and number of phases) and recruitment pattern of MUAPs are the key element for diagnosing pathologies using needle EMG. MUAPs are analyzed per muscle and the results compared with those normally expected for that particular muscle. For this reason, due to the need for a normal pattern, evaluation of MUAPs is not useful to gain deeper knowledge of the role of the muscles in ADL. Parameters, such as time-domain, time-frequency domain, or intensity of muscle activation, could be more useful for studying tasks. EMG data for these purposes are commonly normalized to a reference value to avoid variability arising from electrode placement, participants, or even the day of the experiment. The most popular method is to normalize EMG data to the maximum voluntary contraction (MVC) of the muscle of interest [23], which, besides making data comparable, also informs about how active muscles are relative to their maximum capabilities. Surface EMG is applied in many fields, such as motor control of human movement, myoelectric control of prosthetic and orthotic devices, and rehabilitation [24-27]. Some studies have performed EMG analyses for intrinsic and/or extrinsic hand muscles in specific situations: while grasping objects [28-40], during working postures [41-49], and for the design and improvement of sports equipment, as well as for the study of the role of Muscles in sports performance [50-55].

The concept of synergy has been used in the field of control of myoelectric hand prostheses in an attempt to simplify the study of the complex kinematics and muscular action of the hand [56-59]. There are some studies describing muscle patterns or muscular synergies during some postures [60], grasps [61,62], or hand movements [60,63], and during 
particular actions [64-68]. In that research, different activation patterns have been obtained, revealing coordination between certain intrinsic and extrinsic hand muscles. Thus, EMG patterns have been studied as a way to control signals [69]. However, the usability of myoelectric prostheses is still challenged because of issues, such as the effect of electrode location or changes in EMG patterns over time, which can lead to long training processes [70]. A small number of studies have investigated the existence of hand muscle synergies in ADLs, which could help in the selection of Muscles to control myoelectric prostheses.

In this work, a review of the studies in which EMG has been used to record the muscular activity of hand and forearm muscles during ADL is presented, which may help to identify the role of these muscles in ADLs. In addition, studies examining EMG patterns or muscular synergies between the muscles of the hand and forearm are also presented, in order to simplify the study of the muscular action of the hand. The contents are organized in two sections: muscle activation in different activities and hand muscle synergies (dimensional reduction of EMG).

\section{Materials and Methods}

The literature review consisted in examining research studies that recorded EMG of hand and forearm muscles regarding the activation of these muscles in ADLs, and the dimensional reduction of the muscular action of the hand. A systematic literature search was conducted in the Scopus and PubMed databases until March 2021. Figure 1 shows the flowchart followed. The search was restricted to papers published in English and containing the terms ("Electromyography" and "muscles") and ("thumb" or "finger" or "hand" or "forearm") in the title, abstract, or keywords. Then, a refined search was conducted including different keywords in the title, abstract, or keywords (see Figure 1). Finally, a manual screening was carried out to remove duplicates and reject non-relevant articles.

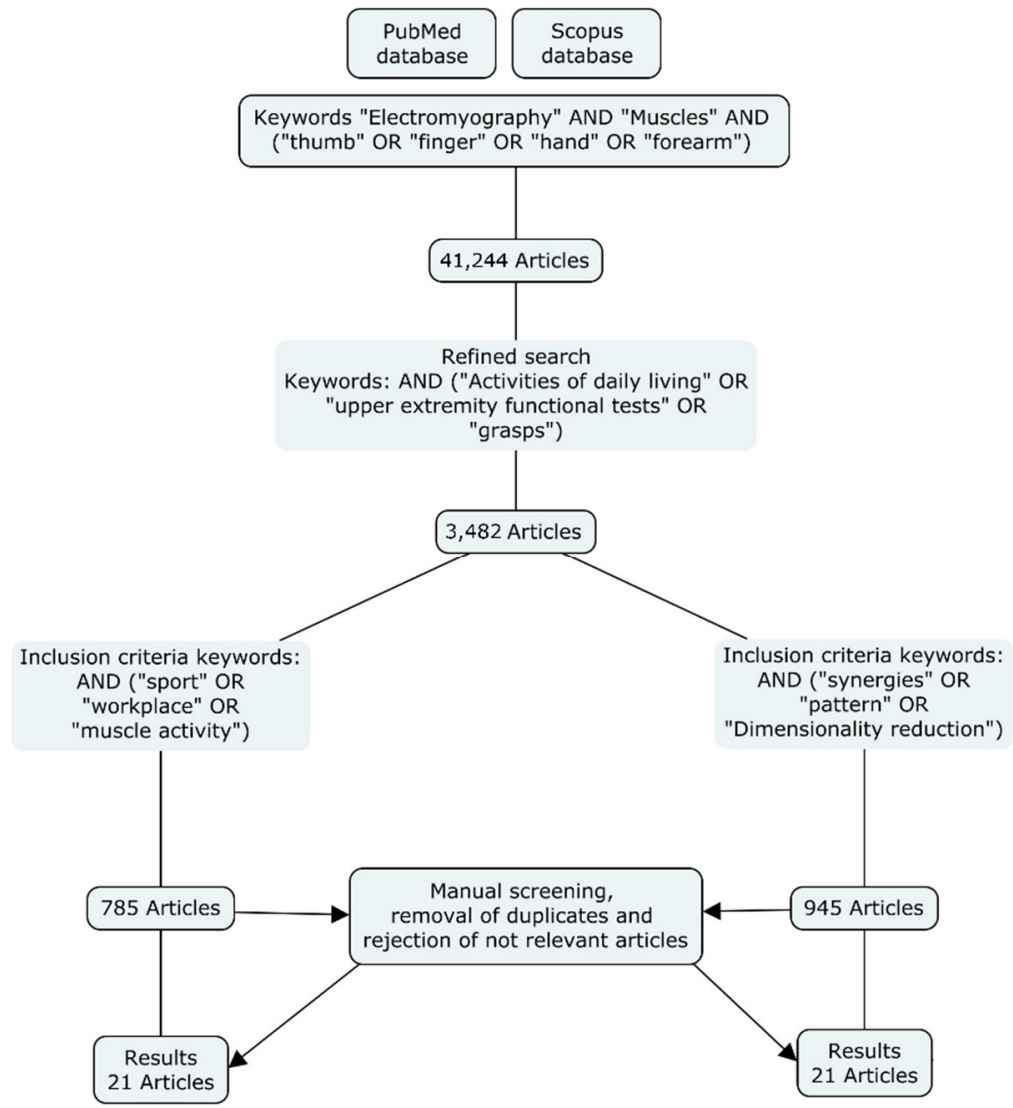

Figure 1. Methodology followed for the literature search. 
After the manual screening, 21 articles related to muscle activity during different ADLs were selected, and 21 articles related to dimensional reduction of EMG of the hand were identified. Altogether, 42 articles (including two reviews) were selected for inclusion in the current review. The articles selected are discussed in the following sections.

\section{Results}

\subsection{Muscle Activation in Different Activities}

This section includes a review of studies that have characterized hand and forearm muscle activity while performing specific activities, such as grasps, ADL, work activities, and sports. Table 2 summarizes the most relevant information of the 21 papers related to muscle activity during different ADL found in the literature.

Several studies have analyzed the activation of hand and forearm muscles (both extrinsic and intrinsic) during certain types of grasps. Regarding extrinsic muscles, they found that in power grasps both the flexor and extensor groups of Muscles (extrinsic muscles) were activated, although the extensor part underwent greater fatigue [47]. As regards the intrinsic muscles, they found that during precision grasps intrinsic muscles play a major role in finely graded force generation, since fine movements require less stabilization and counterforce to the long flexor action [36].

Many studies have focused specifically on the thumb muscle activation through EMG while performing different grasps [30,37-40,71], especially during the opposition movement, due to its great importance in precision grasps. In general, these studies found a need for a cooperation of thumb muscles to accomplish the tasks performed [39], with the exception of the Extensor Policis Longus and Flexor Policis Longus (EPL, FPL), which could be activated separately from the other muscles [40]. Another study [30] explored and demonstrated the importance of the opposition of the thumb during stable and unstable lateral grasps. They observed that instability affects some thumb muscles with greater activation of Abductor Policis Longus (APL) and EPL in the unstable tasks. Similarly, Kaufman et al. [71] recorded the EMG activity of 7 thumb muscles and their contribution at the carpometacarpal (CMC) joint during voluntary isometric contractions. They found that:

- Thumb CMC flexion is supported by Flexor Policis Brevis (FPB), Abductor Policis Brevis (APB), thumb Adductor (ADD), and FPL.

- $\mathrm{CMC}$ extension by APB, APL, and EPL; CMC abduction by FPB, APB, APL, and EPL; and $\mathrm{CMC}$ adduction by FPB, APB, EPL, and FPL.

- The Opponens Policis (OPP) was active in all motions.

However, the studies in the literature all focused on small sets of very controlled and simple activities (a few grasps or simple finger movements). Additionally, they were limited to very specific muscles, or specific fingers or joints, especially for the role of the thumb.

EMG has also been used to study the effect of different kinds of work activities on the forearm muscles, evaluating the influence of different factors on fatigue during repetitive tasks [41,43,49], such as typing, keying, writing, reading and mousing, and on pulling and pushing tasks $[45,46]$. These studies have focused on evaluating and comparing different forearm and hand positions. Nevertheless, the relationship between force production and EMG is not well understood, and there are factors that influence the forces generated and therefore prevent the direct quantification of muscle force from EMG signals. These factors include variations in the location of the recording electrodes, crosstalk, the involvement of synergistic muscles, properties of Muscles, tendons, ligaments, etc. Consequently, the EMG-force relationship differs for each muscle and for each situation [72]. Many studies in the literature have focused on examining muscle activation of both intrinsic and extrinsic muscles in writing activities [31,32,35]. One of these studies [35] compared two different typewriting tasks and the results suggested that the major function of the Extensor Carpi Radialis (ECR) muscle as a stabilizer of the wrist joint is maintained during handwriting. It is also suggested that the increased use of extrinsic muscles could result in a diminished role of intrinsic hand muscles. In that research, the authors showed that EMG of hand and 
arm muscles may be converted into handwriting patterns. However, the results of those studies were focused on specific activities and in many cases with a low number of subjects and activities, lacking representativeness in ADL.

EMG has also been used in the design and improvement of sports equipment, as well as for the study of the role of Muscles in sports performance. Some researchers have studied the regions that are activated, thereby making the main movement possible, in sports, such as golf [50] and tennis [51-54]. Other studies have focused on examining the effect of different features of sports equipment, such as the size of the handle of rackets [53] or of a golf club [55].

Some authors $[50,52]$ have observed that there is considerable diversity in the protocol design used for sEMG recording. For example, most of the studies did not specify the electrode placement, so it is not clear which locations were used to acquire the EMG data, thus making it difficult to compare values. A recent study [73] recorded sEMG activity from 30 spots distributed over the skin of the whole forearm of six subjects while performing 21 representative ADL from the Sollerman Hand Function Test (SHFT). As a result, they proposed that the number of sEMG sensors could be reduced from 30 to 7 without losing any relevant information, using them as representative spots of the muscular activity of the forearm in ADL.

There are few EMG analyses of upper extremities that examine muscle function during daily tasks, and they use little variability and a limited number of tasks (no more than 10) [74-76]. A wide variety of clinical tests (such as the Jebsen Taylor Hand Function (JTHF) test [77], Chedoke Arm and Hand Activity Inventory (CAHAI) [78], or SHFT [79]) are often used to evaluate and track functional recovery of the upper extremity simulating ADL. In these cases, EMG recordings may provide a window into the central nervous system to evaluate muscle recruitment and coordination. In this sense, Peters and collaborators [75] evaluated the recruitment and coordination between several upper-limb muscles during some of these clinical tests (JTHF, CAHAI, and Block and box test (BBT)). Specifically, they recorded sEMG from eight upper-extremity muscles (Anterior and Posterior Deltoid (AD and PD), Biceps Brachii (BB), Triceps lateral head (TriB), Brachioradialis (Br), ECR, Flexor Carpi Ulnaris (FCU), and Extensor Digitorum (EDC)), and evaluated which muscles were used to execute each task and whether activation and co-contraction levels were similar across tasks. As results, they found that co-contraction levels were similar across tests and EDC was found to have the greatest activation levels across all tasks, thereby denoting its importance for common tasks. However, this study has several limitations: they evaluated a small set of forearm muscles (only four forearm and finger muscles).

Summing up, most research found in the literature presents gaps that require further investigation, as, in many cases, the studies are focused on small sets of very controlled and simple activities. Few of them characterize the EMG activity of all the hand muscles while performing representative actions, either by carrying out all possible grasp types required in ADL or by performing a representative and conveniently standardized set of ADL. Furthermore, the lack of a methodology and a standardized protocol hinders the comparison of EMG results between tasks and subjects. Indeed, at the hand level there are few specific recommendations to help in this decision, although results from a recent study [73] could assist in this task, as 7 specific spots were identified as being representative of the muscular activity of the forearm in ADL. In addition, more studies are required to improve the knowledge about the relationship between force production and EMG. 
Table 1. Summary of the studies included in the systematic literature review (I). Relevant information contains subjects, type of EMG used, and muscles recorded in the studies.

Study Relevant Information Description of the Task

Cooney et al. [38]

Kilbreath and Gandevia [80]
8 healthy subjects

Fw-EMG

Extrinsic muscles:

FPL, APL, EPL, EPB

Intrinsic muscles:

ADD, APB, OPP
Isometric $\mathrm{F} / \mathrm{E}$ and $\mathrm{Abd} / \mathrm{Ad}$

thumb movements,

pinch and power grasps
Observations about Role of Muscles

Extensor muscles (EPL, EPB, and APL) were primary and contributed nearly equally to the extension. In flexion, only the FPL was primary.

ADD and APB are primary in adduction but the EPL

(adduction) and OPP

(abduction) contribute significantly.

Three muscles appear to be primary in pinch and power grasp: the ADD, OPP, and FPL.

7 healthy subjects needle EMG

Extrinsic muscles: FPL, FDP Intrinsic muscles: None
Dynamic movements: Lift a weight by flexion of one digit

There is a coactivation of other deep digital flexor muscles and this coactivation increases when the digit flexes at a greater velocity or through a larger angle.

The intrinsic muscles (FDI, FPI, and FLUM) and the long flexors (FDP, FDS) of the index finger, as well as two intrinsic muscles of the thumb (ADD FPB), increase their activity according to the load.

The other thenar muscles (OPP, APB) and the extrinsic muscles of the thumb (FPL, EPL, EPB, and APL) become active only at higher loads and may serve to stabilize joints. The long extensors of the index finger (EDC, EI) were classified as antagonistic, and only act to balance the applied load and maintain joint equilibrium.

The intrinsic muscles play a major role in finely graded force generation since less stabilization and counterforce to the long flexor action are needed, thus releasing the intrinsic muscles for precise force regulation.

9 healthy subjects sEMG

Hägg and Milerad [47]
Extrinsic muscles: FCU, FDS, ECR Longus, ECR Brevis, EDC

Intrinsic muscles: None

Fatigue effects are generally larger on the extensor side although none of the regimes studied were acceptable from point of view of EMG fatigue. 
Table 1. Cont.

\begin{tabular}{|c|c|c|c|}
\hline Study & Relevant Information & Description of the Task & $\begin{array}{l}\text { Observations about Role } \\
\text { of Muscles }\end{array}$ \\
\hline Chow et al. [51] & $\begin{array}{c}7 \text { healthy and skilled tennis } \\
\text { subjects } \\
\text { sEMG } \\
\text { Extrinsic muscles: } \\
\text { FCR, ECR } \\
\text { Intrinsic muscles: None }\end{array}$ & Tennis volley & $\begin{array}{l}\text { In general, the ECR was more } \\
\text { active than the FCR during } \\
\text { the volley, suggesting the } \\
\text { presence of wrist extension } \\
\text { and abduction. }\end{array}$ \\
\hline Kaufman et al. [71] & $\begin{array}{c}5 \text { healthy subjects } \\
\text { Fw-EMG } \\
\text { Extrinsic muscles: } \\
\text { APL, FPL, EPL } \\
\text { Intrinsic muscles: } \\
\text { APB, OPP, FPB, ADD }\end{array}$ & $\begin{array}{l}\text { Isometric thumb motions in } \\
\mathrm{F} / \mathrm{E} \text { and } \mathrm{Abd} / \mathrm{Ad}\end{array}$ & $\begin{array}{l}\text { The FPB was most active in } \\
\text { the range from flexion to } \\
\text { abduction with about } 50 \% \\
\text { activity or less in extension } \\
\text { and adduction. } \\
\text { The OPP displayed activity in } \\
\text { all directions of motion. } \\
\text { The APB displayed maximal } \\
\text { activity in abduction and } \\
\text { abduction-flexion directions. } \\
\text { The ADD was active } \\
\text { during flexion. } \\
\text { The APL was most active in } \\
\text { abduction and/or extension. } \\
\text { The EPL showed the highest } \\
\text { activity during extension in } \\
\text { combination with abduc- } \\
\text { tion/adduction functions. } \\
\text { The FPL was the most active } \\
\text { in flexion and/or } \\
\text { adduction functions. }\end{array}$ \\
\hline Johanson et al. [30] & $\begin{array}{c}7 \text { healthy subjects } \\
\text { Fw-EMG } \\
\text { Extrinsic muscles: } \\
\text { FPL, EPL, EPB, APL } \\
\text { Intrinsic muscles: } \\
\text { APB, ADD, FDI, FPB OPP }\end{array}$ & $\begin{array}{c}\text { Key and opposition pinch } \\
\text { postures between stable and } \\
\text { unstable tasks }\end{array}$ & $\begin{array}{l}\text { Activation patterns are } \\
\text { different between key and } \\
\text { opposition pinch posture and } \\
\text { between stable and unstable } \\
\text { pinch tasks. } \\
\text { APB and EPL muscles are } \\
\text { necessary to accurately direct } \\
\text { thumb-tip forces in a } \\
\text { functional pinch, not just to } \\
\text { position the thumb, } \\
\text { independently of pinch } \\
\text { force magnitude. } \\
\text { In all unstable conditions, } \\
\text { APB and EPL were among the } \\
\text { most activated muscles and } \\
\text { could provide the task with } \\
\text { directional accuracy. }\end{array}$ \\
\hline Van Galen et al. [41] & $\begin{array}{c}20 \text { subjects } \\
\text { sEMG } \\
\text { Extrinsic muscles: } \\
\text { BB, TriB, FCU, ECR } \\
\text { Intrinsic muscles: None }\end{array}$ & $\begin{array}{l}\text { Fast movements with an } \\
\text { electronic pen along the } \\
\text { surface of a digitizer }\end{array}$ & $\begin{array}{l}\text { For the forearm muscle } \\
\text { movers, our findings show } \\
\text { that the participants reacted } \\
\text { with a substantial increase in } \\
\text { static muscle activity, i.e., of } \\
\text { antagonistic activation. } \\
\text { For the wrist stabilization } \\
\text { musculature, however, the } \\
\text { effect was reversed. }\end{array}$ \\
\hline
\end{tabular}


Table 1. Cont.

\section{Study \\ Relevant Information \\ Description of the Task}

7 healthy subjects

$$
\text { sEMG }
$$

Danion and Galléa [37]

Extrinsic muscles: EPL

Intrinsic muscles: FPB during precision grasp
Observations about Role of Muscles

Muscle co-contraction is not a critical factor for force steadiness during a precision grasp task.

Constant force matching task Muscle co-contraction and grip force steadiness depend on grip force magnitude, but grip force steadiness does not depend on muscle co-contraction.

There was a progressive increase in ECRL and FCR activity from early acceleration through

16 healthy tennis players

Fw-EMG

Extrinsic muscles:

Hatch et al. [53] EDC, ECR Longus, ECR Brevis, PT, FCR

Intrinsic muscles: None
Back-hand tennis stroke

ball impact.

There was a progressive increase in EDC activity through the early and late acceleration phases.

At ball impact, all muscle activity tended to peak, and then gradually decreased in the early follow-through phase.

Elite archers relax their finger flexors so as not to grip the bow-handle, and contract the extensors to avoid holding/gripping the handle throughout the whole shot. The main difference between elite and beginner archers was that the elite archers had a greater activation of the EDC.

6 healthy subjects sEMG

Extrinsic muscles:

Linderman et al. [32] FCR, EDC, ECU, ECR Intrinsic muscles: OPP, APB, FDI

12 healthy subjects sEMG

Extrinsic muscles:

Di Dominizio and Keir [46] FCR, FCU, FDS, ECR, ECU, EDC, AD, PD

Intrinsic muscles: None
It is feasible to recreate handwriting solely from EMG signals thanks to the existence of muscle patterns during writing.

Flexor muscle activity tended to be lower when performing push with grip tasks and pull with grip tasks than extensor muscle activity. The highest wrist and finger extensor (ECR, ECU, and EDC) activity was elicited when performing grip tasks in a pronated posture.

ECU was found to be the most sensitive to postural changes. 
Table 1. Cont.

\section{Study \\ Relevant Information \\ Description of the Task}

17 healthy subjects and 9 symptomatic office workers sEMG

Szeto and Lin [49]

Extrinsic muscles:

ECR, FCU, ECU, FCR

Intrinsic muscles:

None
Performing mouse-clicking tasks under different speed and precision conditions
Observations about Role of Muscles

Higher EMG amplitudes in the Control Group over Case Group mostly in the ECU and ECR muscles and more so in the more stressful condition. ECR muscle recorded significant group differences in both precision and speed condition analyses, and FCU in speed condition analysis.

Higher peak activity in the leading PT during the acceleration phase and just after the impact in professional golfers compared to amateur players who showed peak activation in the ECRB.

and professional golfers sEMG/Fw-EMG
Marta et al. [50]

Extrinsic muscles:

ECR Brevis, PT,

FCR, FCU,

Different phases of the golf swing

Intrinsic muscles:

None

This study also reported considerably higher levels of activity in the ECRB in amateurs during all swing phases.

Some studies did not specify the electrode placement, so it is not clear which locations were used to acquire the EMG data, thus making it difficult to compare values.

The major function of the ECRB muscle as a stabilizer of the wrist joint is maintained during handwriting tasks and

Almeida et al. [35]

24 healthy subjects sEMG

Extrinsic muscles:
Tr, BB, ECR Brevis, FDS Intrinsic muscles: None

Writing a word five times the increased use of extrinsic muscles could result in a diminished role of intrinsic hand muscles during handwriting.

Only two extrinsic thumb muscles, EPL and FPL, were capable of sustaining individual activations from the other thumb muscles. Activation of EPB elicited coactivity levels from EPL and APL.

Activating each specific APL, EPB, EPL EDC, FDP, FDS, FPL muscle during $3 \mathrm{~s}$ of MVC

Intrinsic muscles: None

36 healthy subjects

sEMG

Extrinsic muscles:

Park [31]
FCU, FCR, ECU, ECR Upper $\mathrm{Tr}$

Intrinsic muscles:
ECU was the most active

Writing subtests of the JHFT muscle during witing in left- and right-handers. None 
Table 1. Cont.

Study Relevant Information Description of the Task

Observations about Role of Muscles

Increase in the activity of wrist extensors including ECR Brevis and ECR Longus in multiple phases of forehand, serve, and backhand strokes with the activity of wrist flexors remaining fairly constant. Higher EMG activity of ECR during repetitive pre- and post-impact in the presence of unchanged FCR activity has

Review paper: 198 healthy (controls) 18 Lateral-epicondylitis patients

Alizadehkhaiyat and Frostick [52]
sEMG/Fw-EMG

Extrinsic muscles:

FCU, FCR, ECR, ECU, PT

Intrinsic muscles:

None

Different tennis strokes

been suggested as

predisposing players to injury

or delaying the

recovery process.

Finally, an earlier, longer, and greater activation of ECR

Brevis during backhand volleys at combined conditions of velocity and racket-head impact locations has been reported in LE patients compared to non-injured players.

There was considerable diversity in the protocol design used for EMG recording.

Extrinsic thum significantly more active than intrinsic muscles in all tasks.

10 healthy subjects Fw-EMG

Kerkhof et al. [39]

Extrinsic muscles:

FPL, EPB, EPL, APL

Intrinsic muscles:

ADD, APB, FPB OPP
Isometric contractions in a lateral key pinch, a power grasp, and a jar twist task The thumb muscles display a high variability in muscle activity during functional tasks of daily life.

To produce a substantial amount of force, a co-contraction between the intrinsic and extrinsic thumb muscles is necessary.

Minimal muscle force is required to perform these tests.

20 healthy subjects sEMG

Extrinsic muscles:

Peters et al. [75]
$\mathrm{AD}, \mathrm{PD}, \mathrm{BB}, \mathrm{TriB}, \mathrm{BB}, \mathrm{ECR}$

Longus, FCU, EDC

Intrinsic muscles: None
Clinical tests of upper extremity function
Co-contraction levels were similar across tests.

EDC has the greatest activation levels across all tasks.

The results suggest that healthy participants used different strategies to execute the tests. 
Table 1. Cont.

\begin{tabular}{|c|c|c|c|}
\hline Study & Relevant Information & Description of the Task & $\begin{array}{l}\text { Observations about Role } \\
\text { of Muscles }\end{array}$ \\
\hline
\end{tabular}

The EMG sensors needed to record relevant information about forearm muscle activity could be reduced to 7 . The signals from these seven spots would be related to seven different movements:

6 healthy subjects
sEMG
Extrinsic muscles:
Jarque-Bou et al. [73] $\quad 21$ ADL selected and adapted
Muscles recorded from all the
forearm
Intrinsic muscles:
None

1. wrist flexion and ulnar deviation

2. wrist flexion and radial deviation

3. digit flexion

4. thumb extension and abduction/adduction

5. finger extension

6. wrist extension and ulnar deviation

7. wrist extension and radial deviation
Minimal muscle force is required to perform ADL. Greater activity is shown during reaching (to place the
hand to grasp) than during manipulation.
Finger and wrist extensors were the most active muscles while performing ADL. Muscle activity presented some variability among subjects, highlighting the different possibilities that each subject may have to carry out the same activities.

22 healthy subjects sEMG

Extrinsic muscles:

Jarque-Bou et al. [81] Seven spots representative of all available muscle activity of the whole forearm Intrinsic muscles: None

\section{Abbreviations: FLUM—First Lumbrical; FDI—First Dorsal Interosseous; FPI—First Palmar Interosseous; ECU—Extensor Carpi Ulnaris;} PT-Pronator Teres; FCR—Flexor Carpi Radialis; FDS—Flexor Digitorum Superficialis; FDP—Flexor digitorum Profundus.

\subsection{Hand Muscle Synergies}

This section includes a review of studies that have characterized hand and forearm muscle activity by studying EMG patterns or muscular synergies between the muscles of the hand and forearm in order to simplify the study of muscular action of the hand. Table 2 summarizes the most relevant information in the 21 papers related to hand muscle synergies that were selected.

The human hand has a complex biomechanical structure, controlled by a neural structure that is still not completely understood. In the analysis of the biomechanical and behavioral aspects of the hand, one of the most striking is the high redundancy of its structure, seemingly having many more muscles than are actually required [56]. Synergies are thought to be used by the nervous system to simplify the control of these numerous muscles by actuating them in task-relevant subgroups. There are studies both for and against muscle synergies [82]. Many researchers seek to detect and describe such simplifying functional muscle groups and how to interpret them in order to reveal the underlying control strategy used by the brain to coordinate muscles $[56,60]$. Others point out the importance of the ability of the brain to break and dissolve such patterns 
of neural synchrony. This might happen to enable flexible and individuated control of hand muscles [83-85], thus indicating that muscles are recruited flexibly in accordance with their mechanical action, rather than in fixed groupings. In both cases, EMG of hand muscle activity has been extensively used to infer the control strategies underlying the complex coordination of muscle activity within and across digits and as a tool to study the spatial and temporal coordination of multiple muscles. In fact, this technique has been used to examine the organization of these muscle synergies in healthy and neurologically impaired individuals $[83,86]$. In addition, several studies have examined the covariations in EMG amplitudes across muscle pairs [36] and among multiple muscles $[87,88]$ related to hand function.

Previous studies reinforce the idea of hand muscle synergies, and their results concerning the features of hand muscle synergies can be summarized as: muscle synergy occurs primarily across muscles with similar mechanical features [89]; the coactivity of some muscles is a way to adapt the limb to different environmental conditions [90,91]; and the whole set of hand and forearm muscles may be approximated with relatively few adequately scaled and synchronized muscle synergies [60,92-96].

The basic approach of these studies involves four steps:

(1). Measuring sEMG from a large number of Muscles during a complex behavior (or more than one behavior). Note that surface electrodes are the most widely used method, since they are non-invasive and a high number of Muscles on the forearm need to be recorded.

(2). Using a computational analysis, such as non-negative matrix factorization, to identify a set of synergies from the sEMG recorded. Different factorization methods have been used to extract muscle synergies from muscle activation patterns during dynamic tasks. The two most commonly used factorization methods reported in the literature are non-negative matrix factorization and principal component analysis [97]. Similar results are obtained in both cases, but the non-negative matrix factorization method is the most suitable when recording a high number of channels [98].

(3). Evaluating whether the sEMG observed can be well described as the combination of these synergies.

(4). Relating the muscle synergies identified to task-relevant variables [82].

As a result of the application of this procedure, two different types of synergies are described in the literature: synchronous synergies and time-varying synergies. A synchronous synergy is a vector of weighting coefficients that specify the relative involvement (strength of membership) of each muscle in the group. In contrast, a time-varying synergy is a collection of EMG bursts in various muscles.

Several studies describe muscle patterns or muscular synergies during certain specific postures or grasps [99] or during the whole-hand grasping performance [60,62]. Some synergies during specific tasks are also described, such as during finger spelling [60,95], or the preparatory muscle activation response when a fall occurs [100]. Weiss and Flanders [60] recorded the EMG activity of 6 hand and forearm muscles (APB, FPB, FDI, EDC, ADM, and FDS) in four subjects while they held the hand statically, shaping around 26 grasped objects and forming the 26 letter shapes of a manual alphabet. They found that a single muscle can be a member of more than one muscle synergy $[60,101]$. Klein Breteler et al. [95] expanded the synergy analysis from static synergies to time-varying synergies in order to explore the timing of muscle activations during finger spelling using a manual alphabet. They recorded FDI, APB, FPB, ADM, FDS, and EDC and concluded that four time-varying synergies could account for $80 \%$ of the temporal EMG patterns observed, with the first two synergies accounting for about $60 \%$. In addition, they showed that the first component displayed a consistent pattern, the first and second component waveforms showed similarities across subjects, and higher order components were far more variable across subjects. The first component was a pattern where the EDC and the thumb muscles (APB and FPB) were active early on, and the other muscles were active later. Recently, Scano and collaborators [62] extracted muscle synergies from 20 hand grasps with an array of 8 equally spaced electrodes 
on the forearm, two electrodes on finger flexors and extensors, and another two on BB and TriB. The synergies they found were characterized by two temporal activation patterns: a strong coactivation corresponding to the grasp/hold phase, and two minor coactivating patterns related to hand opening (visible in the pre-shaping and release phase).

Synergistic finger patterns have also been described during dynamic free movements of the wrist and single fingers [102-104]. Tanzarella et al. [104] performed isometric contractions with each finger and with three combinations of fingers in opposition with the thumb. They observed a low dimensional control of motor neurons across multiple intrinsic and extrinsic muscles. Gazzoni et al. [102] identified distinct areas of sEMG activity on the forearm for different fingers during hand and finger movements. In the same way, Hu et al. [103] revealed distinct activation patterns during individual finger extensions, especially for the index and middle fingers. Nevertheless, the detailed location of the recording electrodes was not reported in most of the studies, which makes comparison between subjects and activities difficult.

However, few studies have assessed muscle patterns during complex tasks in which manipulation is the most relevant phase, such as in ADL $[61,68]$, or during particular actions, such as playing a piano [63], archery [65,67], catching a ball [64], or while performing a karate punch [66]. Winges et al. [63] studied the muscle activation patterns of 10 pianists, suggesting that amateur pianists use the same balance as professionals. Nevertheless, in other research $[65,67]$, the authors found different patterns between elite and beginner archers, where the main difference was that the expert archers had a greater activation of the ED. In this sense, in a study on karate punches [66], expert and non-expert karatekas presented distinct kinematic and EMG patterns. Regarding a more complex activity, such as catching a ball [64], the authors recorded sEMG data from 16 shoulder and elbow muscles, but only one forearm muscle $(\mathrm{Br})$, in six subjects. They found that the variation in the muscle patterns was captured by two time-varying muscle synergies, modulated in amplitude and shifted in time according to the height at which the ball arrived and the flight duration. The initial muscular response, captured by the first synergy, allowed the subject's hand to reach the interception zone. The following component of the muscle pattern, captured by the second synergy, guided the hand to the interception. Zariffa et al. [61] characterized what muscle synergies were present while using different types of hand grips (gripping a block, a cylinder, a ball, a key, and rotating a disk 180 degrees) extracted from clinical tests. sEMG data was recorded from FDI, FCU, FCR, FDS, ECR, EDC, EIP, and the thenar eminence muscle group. Two main synergies were found: the first between EDC and EIP, and the second between FDS and FCU. However, they had some limitations due to crosstalk, the small number of Muscles recorded, and the little variability of the ADLs chosen. Ricci et al. [68] recorded data from shoulder and elbow muscles along with FDS, FCU, ECRLB, and ECU while subjects poured water. In the transport phase, characterized by weight bearing, handgrip and displacement of the arm in space, a higher activity of almost all muscles was found. Furthermore, they found that ECR seems to play a key role in maintaining optimal wrist posture and function regardless of task demand. That stabilization could be provided by a delicate balance of co-contraction of forearm muscles to keep the hand in the proper posture to grasp or produce handgrip force [105]. However, few forearm muscles were measured and for very specific actions, and therefore further studies should be conducted to evaluate more forearm muscle patterns in a wide range of ADL. Likewise, hand kinematics should be recorded in order to relate muscular and kinematic hand synergies during representative ADL.

Moving on to the assessment of pathologies, as mentioned above, sEMG has recently been used for the evaluation of patients with neuromuscular disorders by using muscle synergies. Muscle synergies have been investigated in acute, subacute, and chronic stroke, showing abnormalities compared to healthy people [84,106-109], as well as in patients with dystonia [110] and sclerosis [111] or after spinal cord injury [61]. The results illustrate that muscle synergy patterns contain rich information in their spatial components and temporal profiles. Comparing pathological synergies of patients with the baseline synergy 
can reveal deficits in the underlying neuromuscular coordination and control. The analysis of task-specific muscle synergies should offer both researchers and clinicians new insights into the impairments in the neural organization of motor control. Yet, in these studies, a considerable diversity in the protocol design was used for sEMG recording, and it is not clear which locations were used to acquire the sEMG data, resulting in difficulty when it comes to comparing values.

Summarizing, EMG has been widely used to detect muscle patterns, although a small number of studies have investigated the muscular synergies in the hand in greater depth. There are some gaps that need to be studied in more detail. First, muscular synergies seem to be task-dependent, and a single muscle can be a member of more than one muscle synergy. In the literature, researchers have generally investigated the presence of synergies during some specific hand movements or grasps, but few studies have analyzed the different coordination and muscular patterns or synergies during the performance of a representative set of ADL. Second, little has been studied about kinematics and muscular synergies of the forearm and hand relationship. Consequently, little is known about the role of the muscles linked to the joint movement of the hand during ADL.

Table 2. Summary of the studies included in the systematic literature review (II). Relevant information contains subjects, type of EMG used, and muscles recorded in the studies.

Study Relevant Information $\quad$ Description of the Task $\quad \begin{gathered}\text { Observations about } \\ \text { Muscles Role }\end{gathered}$

CNS is implementing the predicted mechanically advantageous strategies, and scaling them down to produce less than maximal forces.

8 healthy subjects Fw-EMG

Valero-Cuevas et al. [87] Extrinsic muscles: FDP, FDS, EI, EDC Intrinsic muscles: FLUM, FDI, FPI
Static force in five directions

Palmar force used flexors, extensors, and FDI. Dorsal force used all muscles. Distal force used all muscles except for extensors.

Medial and lateral forces used

all muscles including significant co-excitation of FDI.

Significant muscle coordination patterns similar to those previously reported for $100 \%$ of maximal fingertip forces were found for $50 \%$ of maximal voluntary force.

Single muscles may be a member of more than one muscle synergy.
Static postures for 26 objects and 26 letter shapes of a manual alphabet

Different levels of fingertip forces while maintaining the forefinger in a static posture
Weiss and Flanders [60]

Extrinsic muscles: EDC, FDS

Intrinsic muscles:

ADM, APB, FPB, FDI

The first synergy represented the main temporal synergy, accounting for more of the EMG variance (up to $40 \%$ ).

9 healthy subjects sEMG

Klein Breteler et al. [95]

\section{Extrinsic muscles:} EDC, FDS

Intrinsic muscles:

FDI, APB, FPB, ADM
Finger spell words, presented on a computer screen
This main synergy began with a burst in the EDC and a silent period in the flexors. There were then progressively later and shorter bursts in the APB, FPB, ADM, and, finally, the FDS. 
Table 2. Cont.

$\begin{array}{llll}\text { Study } & \text { Relevant Information } & \text { Description of the Task } & \begin{array}{l}\text { Observations about } \\ \text { Muscles Role }\end{array}\end{array}$

Martelloni et al. [96]

Valero-Cuevas et al. [85]
6 healthy subjects

$$
\text { sEMG }
$$

Extrinsic muscles:

TriB, Deltoid, Trapezius, FCR, ECR, BB

Intrinsic muscles: None
Performing reach-to-grasp movements for different objects placed in different locations

Activation of proximal muscles can be statistically different for different grip types.

Proximal and distal muscles are simultaneously controlled during reaching and grasping. Patterns of EMG activation in arm muscles can provide a reliable representation of motor behavior during reaching and grasping of different objects.

Evidence for preferential control of task-relevant parameters that strongly suggest the use of a neural control strategy compatible with the principle of

8 healthy subjects Fw-EMG

Extrinsic muscles: EDC, EI, FDP, FDS Intrinsic muscles: FDI, FPI, FLUM
Vertical fingertip force vectors of prescribed constant or time-varying magnitudes minimal intervention.

Only one synergy accounting for $>40 \%$ of the variance with positive correlation among all muscles (coactivation).

There was no reduction in dimensionality because each of the seven principal components explains a nontrivial amount of variance.

FDI in the control hand was active only when the index finger was abducting. FDI in the affected hand was also active during movement of the thumb or the ring finger. These inappropriate contractions of FDI in the affected hand would cause the index finger to move when the subject attempted to move only the thumb or the ring finger.

Muscle synergies of the stroke-affected arm were strikingly similar to those of the unaffected arm despite marked differences in motor performance between the arms.

In subjects with severe motor impairment, there was far less resemblance between the synergies of the two arms. 
Table 2. Cont.

\section{Study}

VencesBrito et al. [66]
18 karatekas and 19 non-karatekas sEMG

Extrinsic muscles: BB, Br, Deltoid, Pectoralis, PT, Infraspinatus Intrinsic muscles: None
Analysis of a karate punching movement (choku-zuki) on a fixed target
Cheung et al. [107]

\section{1 stroke subjects \\ sEMG}

Extrinsic muscles: infraspinatus; rhomboid major; Trapezius; pectoralis major; Deltoid; TriB; BB; brachialis, $\mathrm{Br}$; supinator; $\mathrm{PT}$

Intrinsic muscles: None
Tasks and reaching movements with shoulder and forearm motions
10 healthy subjects

6 Spinal cord-injured subjects sEMG

Zariffa et al. [61]
Extrinsic muscles: FDS, FCR, FCU, ECR, EDC Intrinsic muscles:

EI, FDI, Thenar eminence
7 functional tasks using grasp types relevant to ADLs

\section{Observations about Muscles Role}

The two groups presented distinct EMG patterns. The first muscles to be activated were the agonists of the arm flexion and internal rotation.

This was followed by an initial activation of the forearm flexor and pronator muscles. The forearm extensor muscle initiates its activity slightly later, followed by the second activation moment of forearm pronator muscle.

Muscle synergies of the stroke-affected arm were strikingly similar to those of the unaffected arm despite marked differences in motor performance between the arms.

In subjects with severe motor impairment, there was much less resemblance between the synergies of the two arms.

The synergies found were: (1) EDC and EIP, and (2) FDS and FCU.

Many tasks involving finger extension tasks can be expected to recruit both EDC and EIP.

The FDS and FCU synergy suggests that a wrist flexion was often used to position the hand during a grasping action, though this may be a product of the specific set of tasks employed in this study. The most common synergy in SCI subjects was FCR and ECR, which was also one of the average able-bodied synergies. FDI and Thenar eminence were common in both groups, possibly because of the need for independent fine thumb and index finger movements in many dextrous tasks. In subjects with SCI, similar synergies were observed, but in different proportions. 
Table 2. Cont.

\begin{tabular}{|c|c|c|c|}
\hline Study & Relevant Information & Description of the Task & $\begin{array}{l}\text { Observations about } \\
\text { Muscles Role }\end{array}$ \\
\hline Burkhart and Andrews [100] & $\begin{array}{c}20 \text { healthy subjects } \\
\text { sEMG } \\
\text { Extrinsic muscles: } \\
\text { BB, Br, Anconaeus, FCR, ECR } \\
\text { Intrinsic muscles: } \\
\text { None }\end{array}$ & $\begin{array}{l}\text { Impacts occurred to the hand } \\
\text { from two heights }\end{array}$ & $\begin{array}{l}\text { Individuals are capable of } \\
\text { selecting an upper extremity } \\
\text { posture that allows them to } \\
\text { minimize the effects of an } \\
\text { impact and the presence of a } \\
\text { preparatory muscle activation } \\
\text { response has been confirmed. }\end{array}$ \\
\hline $\begin{array}{c}\text { Castellini and } \\
\text { Van Der Smagt [99] }\end{array}$ & $\begin{array}{c}6 \text { healthy subjects } \\
\text { sEMG } \\
\text { Extrinsic muscles: } \\
\text { Two bands surrounding the } \\
\text { forearm } \\
\text { Intrinsic muscles: } \\
\text { None }\end{array}$ & $\begin{array}{c}\text { Five static grasps: flat grasp, } \\
\text { pinch grip, tripodal grip, } \\
\text { small power grasp, and large } \\
\text { power grasp }\end{array}$ & $\begin{array}{l}\text { Three main synergies were } \\
\text { found: uniform activation, } \\
\text { activation of the dorsal } \\
\text { muscles near the radius, and } \\
\text { activation of the flexors near } \\
\text { the radius. }\end{array}$ \\
\hline Lee et al. [109] & $\begin{array}{c}4 \text { healthy subjects } \\
14 \text { subjects with chronic } \\
\text { hemiparesis } \\
\text { sEMG } \\
\text { Extrinsic muscles: FDS, EDC, } \\
\text { FCR, FCU, ECR, ECU } \\
\text { Intrinsic muscles: } \\
\text { Thenar muscles, FDI, } \\
\text { hypothenar muscles }\end{array}$ & $\begin{array}{l}\text { Wrist } \mathrm{F} / \mathrm{E} \text { finger extension, } \\
\text { lateral pinch, power grip, and } \\
\text { tip pinch }\end{array}$ & $\begin{array}{l}\text { The first synergy, containing } \\
\text { mainly thenar and FDI } \\
\text { activity, was largely active in } \\
\text { the three grip tasks. } \\
\text { The second synergy, } \\
\text { consisting of EDC, ECR, and } \\
\text { ECU, was heavily weighted } \\
\text { during finger/wrist extension. } \\
\text { The third synergy, involving } \\
\text { coactivation of the wrist and } \\
\text { finger muscles. } \\
\text { The fourth synergy, with FCR, } \\
\text { FCU, and EDC activity, was } \\
\text { employed during } \\
\text { wrist flexion. } \\
\text { For stroke survivors, the } \\
\text { composition of these modules } \\
\text { was generally similar to those } \\
\text { of subjects with } \\
\text { no impairment. }\end{array}$ \\
\hline Winges et al. [63] & $\begin{array}{l}10 \text { healthy subjects } \\
\text { sEMG } \\
\text { Extrinsic muscles: } \\
\text { FDS ( } 2 \text { portions), EDC } \\
\text { Intrinsic muscles: } \\
\text { ADM, APB, FPB, FDI }\end{array}$ & $\begin{array}{l}\text { Piano dynamic movements: } \\
\text { playing } 14 \text { selected pieces } \\
\text { with the right hand at a } \\
\text { uniform tempo }\end{array}$ & $\begin{array}{l}\text { Phasic coactivation was } \\
\text { evident between extensor and } \\
\text { flexor muscles during } \\
\text { piano playing. } \\
\text { For the thumb sequence, PC1 } \\
\text { first synergy was dominated } \\
\text { by bursts of activity in the } \\
\text { APB and the FPB with activity } \\
\text { in the four-finger ED muscle. } \\
\text { For the index finger sequence, } \\
\text { the central burst of the first } \\
\text { synergy included activity in } \\
\text { two to three flexors of the } \\
\text { index finger. } \\
\text { Higher PC synergies were } \\
\text { variable across subjects. }\end{array}$ \\
\hline
\end{tabular}


Table 2. Cont.

\section{Study}

Hu et al. [103]
10 healthy subjects sEMG

Extrinsic muscles: surface grid centered on the EDC

Intrinsic muscles: None
Static and dynamic finger movements: To extend MCP joints individually
Description of the Task

\section{Observations about Muscles Role}

When the four fingers were extended simultaneously, the entire EDC was active.

When individual fingers were extended separately, distinct regions of the EDC were selectively activated, with the index finger in the most distal region, the middle finger in the most proximal region, and the ring and little fingers in between.

Index and middle fingers have a greater degree of individuation in comparison to the little and ring fingers.

In the reaching phase, the main movements observed were shoulder flexion and elbow and wrist extension, accompanied by significant higher activity of S, D, and TriB.

The sequence of movements in this phase ended up with the subjects grasping the pitcher, which could be related to the late coactivation between ECU and FCU.

Transport phase was mainly characterized by higher muscle activity of all muscles, except for Pectoralis.

There were almost no significant differences in muscle activity within the release phase.

ECR is a key muscle for wrist posture and function regardless of the task demand. Activation of FCU and ECRLB were identified as the main control strategy performed to maintain optimal grasping.

EMG spatial patterns were well explained by task-dependent combinations of only a few (typically 4) muscle synergies.

6 healthy subjects 16 post-stroke subjects sEMG

Roh et al. [108]
Extrinsic muscles:

$\mathrm{Br}, \mathrm{BB}, \mathrm{TriB}$, Deltoid, and pectoralis

Intrinsic muscles:

None
Grasping the MACARM's gimbaled handle
Elbow-related synergies were conserved across stroke survivors, regardless of level of impairment.

Alterations in the shoulder muscle synergies underlying isometric force generation appear prominently. 
Table 2. Cont.

\section{Study}

24 post-stroke subjects sEMG

Extrinsic muscles: Trapezius, Deltoid medius, BB, ECR, FCR, FDI

Intrinsic muscles: None 14-day program focused on the more- affected upper limb

(

\section{Observations about Muscles Role}

The profile of coordinated muscle activation varied by the level of residual motor-function in chronic stroke.

The number of synergies used increased (although not significantly) with therapy for patients with low and moderate motor-function. The distribution of muscle weightings within synergies changed as a consequence of therapy.

Synergy analysis revealed no difference in the number of synergies between children with and without dystonia. Two synergies primarily involved upper limb distal muscles (distal synergies). Distal synergies were different depending on the task. The other two synergies mainly included proximal muscles (proximal synergies). Proximal synergies were very similar across groups and tasks: Synergy 3 involved shoulder flexors (D), while synergy 4 mainly comprised shoulder extensors (D and supraspinatus).

For both populations, the analysis identified three primary synergies that involved the distal muscles, another synergy that involved proximal muscles, and the last synergy included shoulder muscles. Muscle synergy analysis detected aspects related to muscle coordination that were not evident from the analysis of single muscle activity. 
Table 2. Cont.

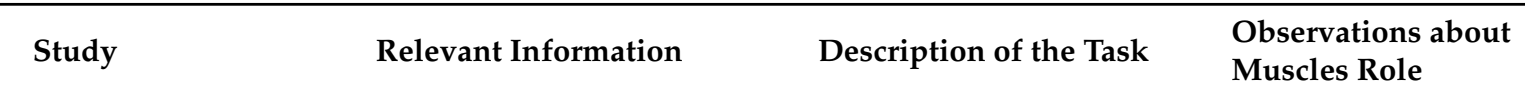

Ten spatial motor modules,
properly elicited in time, are
enough to describe the whole
dataset with good accuracy,
generalizing across subjects.
The coactivating group
composed of forearm
electrodes is very often
grouped together, especially
in the hold phase.
Two activation patterns are
recognizable: a strong
coactivation, often (but not
always) corresponding to the
grasp/hold phase, and two
minor coactivating patterns in
the pre-shaping and release
phases that are often grouped
in a single synergy.
BB is activated during the
reaching phase, thereby
confirming that it is indeed an
active reaching component
that is active in the
pre-shaping and
release phase.

Abbreviations: ADM—Abductor Digiti Minimi; FLUM—First Lumbrical; FDI—First Dorsal Interosseous; FPI—First Palmar Interosseous; ECU—Extensor Carpi Ulnaris; PT-Pronator Teres; FCR—Flexor Carpi Radialis; FDS-Flexor Digitorum Superficialis; FDP—Flexor Digitorum Profundus.

\section{Discussion}

This literature review found 42 papers that matched the defined search criteria: 21 papers regarding the role played by hand and forearm muscles, and 21 dealing with hand muscle synergies.

First, studies focused on the role of specific small sets of forearm/hand muscles during some common tasks and grasps, sport activities, and working tasks were analyzed. Both extrinsic and intrinsic forearm muscles are required to accomplish these tasks, the extrinsic ones being responsible for the gross movements and the intrinsic ones in command of the fine movements, but they also complement each other. Some specific muscles show a high level of activation across all the tasks, such as EDC, while others seem to have a specific role, such as ECR as a wrist stabilizer. The tasks performed in ADL seem to require moderate levels of co-contraction of forearm muscles, needing the cooperation between different groups of Muscles, this cooperation being non task-dependent [75]. Thumb muscles, such as EPL and EPB, are able to activate separately from the flexors and extensors of the other fingers, and their important role in grasps has been widely demonstrated in the literature.

Second, the muscle synergies reflecting the relationship between muscles provide information in two domains: co-contractions and timing of activation. Therefore, studying muscle synergies can help to reach a better interpretation of the role of the muscles during the execution of different movements/tasks. The idea is consistent with the concept that the central nervous system may embed a modular structure that relies on a limited number of synergies at hand level. Non-negative matrix factorization and principal component analysis methods are the most used and present similar results in terms of coordination patterns. However, the non-matrix factorization method is the most preferred when a high number of sEMG are recorded [98]. The studies reviewed have demonstrated that a small 
subset of synergies could be generalized across tasks, representing basic building blocks underlying natural human hand motions/actions. Therefore, muscle synergy analysis could also be useful for comparing different therapies and evaluating the function recovery of subjects regarding ADL performance. It has been hypothesized that patients' functional deficit may be identified by regularly assessing their muscle synergy profile, which might be used to track the results of rehabilitation, and to adjust treatments [113]. Synergies have been suggested as being useful for clinicians to treat motor dysfunctions more effectively by organizing patients into subclasses and tailoring the treatment to each patient's specific deficit [113].

However, some important gaps have also been identified, which should be addressed in further studies. One of the main gaps found in the literature is the considerable diversity in the protocol design used to record sEMG from forearm muscles. Most of the studies do not specify the electrode placement, so it is not clear which locations were used to acquire the sEMG data. This makes it difficult to compare values or may affect the crosstalk level, which will depend on the longitudinal level of the muscle where it has been placed. Therefore, it could be useful to define a method of placing the sEMG electrodes that is comparable between subjects and that considers all the muscles involved in wrist and hand movements. It has been seen that this could be achieved by identifying the most representative forearm areas for ADL performance in terms of EMG activity [73].

The second main gap concerns the lack of representativeness of the tasks used for the EMG characterization. Most studies found in the literature are focused on studying the role of specific muscles during simple tasks (hand postures or free finger movements), or during single activities (such as writing or typing), or during small sets of very controlled activities (a few grasps, sport movement, etc.). However, only a few studies have dealt with the analysis of the forearm and hand muscles during ADL, and none of them consider a wide representative set of ADL. Therefore, defining a selection of a limited set of representative tasks would improve the current methodology, given the wide variety of ADL that can be performed by humans. Furthermore, standardization of the tasks would allow for comparison between subjects and sessions (important for tracking function recovery). The use of standardized tasks is especially important considering that each different individual may perform the same activity using several different strategies. Standardization would help in the comparison of muscular patterns and the identification of different strategies, by distinguishing between the different task phases [114].

In addition, to go further into synergies, simultaneous measurement of hand kinematics is not usually performed, and, when it is measured, it is used only to segment the different phases of the movement. Therefore, linked EMG-kinematic datasets, at the hand level, are very limited [81]. Such synchronized datasets are needed if we want to analyze how hand movements are produced and controlled. This could be helpful in some fields, like rehabilitation (to help choose the most suitable approaches) or prosthetics (to find a more reliable and natural control of hand prosthetics).

The review performed provides a basis of knowledge about the role of hand/forearm muscles, but the lack of a clear methodology introduces some limitations. These methodological inconsistencies add additional difficulty for an effective interpretation of findings and to draw any decisive conclusions.

Author Contributions: Writing-review and editing, N.J.J.-B.; Revision and supervision, M.V. and J.L.S.-B. All authors have read and agreed to the published version of the manuscript.

Funding: This research was funded by the Spanish Ministry of Science, Innovation and Universities (project PGC2018-095606-B-C21), and under a grant from the Spanish MINECO and the European Union (FEDER funds) through project DPI2014-52095-P and FPI grant BES-2015-072480.

Institutional Review Board Statement: Not applicable.

Informed Consent Statement: Not applicable.

Data Availability Statement: The study does not report any data. 
Conflicts of Interest: The authors declare no conflict of interest.

\section{Abbreviations}

\begin{tabular}{|c|c|}
\hline $\mathrm{Ab} / \mathrm{Ad}$ & Abduction/adduction \\
\hline $\mathrm{AD}$ & Anterior Deltoid \\
\hline ADL & Activities of daily living \\
\hline ADM & Abductor Digiti Minimi \\
\hline APL & Abductor Policis Longus \\
\hline APB & Abductor Policis Brevis \\
\hline ADD & Thumb Adductor \\
\hline $\mathrm{BB}$ & Biceps Brachii \\
\hline $\mathrm{Br}$ & Brachioradialis \\
\hline $\mathrm{CMC}$ & Carpometacarpal \\
\hline ECR & Extensor Carpi Radialis \\
\hline ECRB & Extensor Carpi Radialis Brevis \\
\hline ECRL & Extensor Carpi Radialis Longus \\
\hline ECU & Extensor Carpi Ulnaris \\
\hline EDC & Extensor Digitorum Communis \\
\hline EI & Extensor Indicis \\
\hline EMG & Electromyography \\
\hline EPB & Extensor Policis Brevis \\
\hline EPL & Extensor Policis Longus \\
\hline $\mathrm{F} / \mathrm{E}$ & Flexion/extension \\
\hline FCR & Flexor Carpi Radialis \\
\hline FCU & Flexor Carpi Ulnaris \\
\hline FDP & Flexor Digitorum Profundus \\
\hline FDS & Flexor Digitorum Superficialis \\
\hline FDI & First Dorsal Interosseous \\
\hline FLUM & First Lumbrical \\
\hline FPI & First Palmar Interosseous \\
\hline Fw-EMG & Fine-wire EMG \\
\hline iEMG & Intramuscular Electromyography \\
\hline ICF & International Classification of Functioning, Disability and Health \\
\hline IP & Interphalangeal \\
\hline MCP & Metacarpophalangeal \\
\hline MUAPs & Motor unit action potentials \\
\hline MVC & Maximum Voluntary Contractions \\
\hline OPP & Opponens policis \\
\hline PD & Posterior Deltoid \\
\hline PIP & Proximal interphalangeal \\
\hline PL & Palmaris Longus \\
\hline PT & Pronator Teres \\
\hline sEMG & Surface Electromyography \\
\hline SENIAM & Surface electromyography for the non-invasive assessment of Muscles \\
\hline SHFT & Sollerman Hand Function Test \\
\hline $\operatorname{Tr}$ & Trapezius \\
\hline TriB & Triceps Brachii \\
\hline $\mathrm{WHO}$ & World Health Organization \\
\hline WMSD & Work-related musculoskeletal disorders \\
\hline
\end{tabular}

\section{References}

1. Vergara, M.; Gracia-Ibáñez, V.; Sancho-Bru, J.-L.L. Evaluation of Hand Functionality during Activities of Daily Living (ADL): A Review. In Activities of Daily Living, Adl: Cultural Differences, Impacts of Disease and Long-Term Health Effects; Lively, S.T., Ed.; Nova Science Pub Inc.: New York, NY, USA, 2015; pp. 103-132. ISBN 978-1-63463-941-5.

2. WHO. International Classification of Functioning, Disability and Health (ICF); WHO: Geneva, Switzerland, 2001.

3. Vergara, M.; Sancho-Bru, J.L.; Gracia-Ibáñez, V.; Pérez-González, A. An introductory study of common grasps used by adults during performance of activities of daily living. J. Hand Ther. 2014, 27, 1-28. [CrossRef] 
4. Bullock, I.M.; Zheng, J.Z.; Rosa, S.D.L.; Guertler, C.; Dollar, A.M. Grasp Frequency and Usage in Daily Household and Machine Shop Tasks. IEEE Trans. Haptics 2013, 6, 296-308. [CrossRef] [PubMed]

5. Yu, H.-L.; Chase, R.A.; Robert, A.; Strauch, B. Atlas of Hand Anatomy and Clinical Implications; Mosby: St. Louis, MO, USA, 2004; ISBN 0815179278.

6. Kapandji, A.I. Fisiologia Articular. In Miembro Superior -6a ed. Madrid: 2006-2007; Editorial Médica Panamericana: Madrid, Spain, 1996.

7. Brand, P.W.; Hollister, A.M. Clinical Mechanics of the Hand, 3rd ed.; Mosby Publishing: St. Louis, MO, USA, 1999.

8. Lee, K.-S.; Jung, M.-C. Ergonomic evaluation of biomechanical hand function. Saf. Health Work 2015, 6, 9-17. [CrossRef] [PubMed]

9. Oatis, C.A. Kinesiology: The Mechanics and Pathomechanics of Human Movement; Lippincott Williams \& Wilkins: Philadelphia, PA, USA, 2009; ISBN 0781774225.

10. Lum, P.S.; Mulroy, S.; Amdur, R.L.; Requejo, P.; Prilutsky, B.I.; Dromerick, A.W. Gains in Upper Extremity Function After Stroke via Recovery or Compensation: Potential Differential Effects on Amount of Real-World Limb Use. Top. Stroke Rehabil. 2009, 16, 237-253. [CrossRef]

11. Dietz, V.; Schrafl-Altermatt, M. Control of functional movements in healthy and post-stroke subjects: Role of neural interlimb coupling. Clin. Neurophysiol. 2016, 127, 2286-2293. [CrossRef] [PubMed]

12. Elkwood, A.I.; Kaufman, M.; Schneider, L.F. (Eds.) Rehabilitative Surgery; Springer International Publishing: Cham, Switzerland, 2017; ISBN 978-3-319-41404-1.

13. Scheme, E.; Englehart, K. Electromyogram pattern recognition for control of powered upper-limb prostheses: State of the art and challenges for clinical use. J. Rehabil. Res. Dev. 2011, 48, 643. [CrossRef] [PubMed]

14. Hahne, J.M.; Wilke, M.A.; Koppe, M.; Farina, D.; Schilling, A.F. Longitudinal Case Study of Regression-Based Hand Prosthesis Control in Daily Life. Front. Neurosci. 2020. [CrossRef]

15. Roche, A.D.; Lakey, B.; Mendez, I.; Vujaklija, I.; Farina, D.; Aszmann, O.C. Clinical Perspectives in Upper Limb Prostheses: An Update. Curr. Surg. Rep. 2019, 7, 5. [CrossRef]

16. Parker, P.; Englehart, K.; Hudgins, B. Myoelectric signal processing for control of powered limb prostheses. J. Electromyogr. Kinesiol. 2006, 16, 541-548. [CrossRef]

17. Reaz, M.B.I.; Hussain, M.S.; Mohd-Yasin, F. Techniques of EMG signal analysis: Detection, processing, classification and applications (Correction). Biol. Proced. Online 2006, 8, 163. [CrossRef]

18. Chowdhury, R.H.; Reaz, M.B.I.; Ali, M.A.B.M.; Bakar, A.A.A.; Chellappan, K.; Chang, T.G. Surface Electromyography Signal Processing and Classification Techniques. Sensors 2013, 13, 12431-12466. [CrossRef]

19. Khokhar, Z.O.; Xiao, Z.G.; Menon, C. Surface EMG pattern recognition for real-time control of a wrist exoskeleton. Biomed. Eng. Online 2010, 9, 41. [CrossRef]

20. Kamen, G.; Gabriel, D.A. Essentials of Electromyography; Human Kinetics: Champaign, IL, USA, 2010 ; ISBN 9780736085502.

21. Mogk, J.P.M.; Keir, P.J. Crosstalk in surface electromyography of the proximal forearm during gripping tasks. J. Electromyogr. Kinesiol. 2003, 13, 63-71. [CrossRef]

22. Holobar, A.; Farina, D.; Gazzoni, M.; Merletti, R.; Zazula, D. Estimating motor unit discharge patterns from high-density surface electromyogram. Clin. Neurophysiol. 2009. [CrossRef] [PubMed]

23. Konrad, P. The ABC of EMG A Practical Introduction to Kinesiological Electromyography; Noraxon: Scottsdale, AZ, USA, 2005; pp $1-60$.

24. Kumar, D.; Poosapadi Arjunan, S.; Singh, V. Towards identification of finger flexions using single channel surface electromyography_Able bodied and amputee subjects. J. Neuroeng. Rehabil. 2013, 10, 50. [CrossRef] [PubMed]

25. Rojas-Martínez, M.; Mañanas, M.A.; Alonso, J.F. High-density surface EMG maps from upper-arm and forearm muscles. J. Neuroeng. Rehabil. 2012, 9, 85. [CrossRef] [PubMed]

26. Castellini, C.; Fiorilla, A.E.; Sandini, G. Multi-subject/daily-life activity EMG-based control of mechanical hands. J. Neuroeng. Rehabil. 2009, 6, 41. [CrossRef]

27. Hogrel, J.-Y. Clinical applications of surface electromyography in neuromuscular disorders. Neurophysiol. Clin. Neurophysiol. 2005, 35, 59-71. [CrossRef]

28. Bonnefoy, A.; Louis, N.; Gorce, P. Muscle activation during a reach-to-grasp movement in sitting position: Influence of the distance. J. Electromyogr. Kinesiol. 2009, 19, 269-275. [CrossRef]

29. Hoozemans, M.J.M.; Van Dieën, J.H. Prediction of handgrip forces using surface EMG of forearm muscles. J. Electromyogr. Kinesiol. 2005, 15, 358-366. [CrossRef]

30. Johanson, M.E.; Valero-Cuevas, F.J.; Hentz, V.R. Activation patterns of the thumb muscles during stable and unstable pinch tasks. J. Hand Surg. Am. 2001, 26, 698-705. [CrossRef] [PubMed]

31. Park, S. Comparison of Muscle Activation during Dominant Hand Wrist Flexion when Writing. J. Phys. Ther. Sci. 2013, 25, 1529-1531. [CrossRef] [PubMed]

32. Linderman, M.; Lebedev, M.A.; Erlichman, J.S. Recognition of handwriting from electromyography. PLoS ONE 2009, 4. [CrossRef]

33. Duque, J.; Masset, D.; Malchaire, J. Evaluation of handgrip force from EMG measurements. Appl. Ergon. 1995, 26, 61-66. [CrossRef]

34. Kamavuako, E.N.; Farina, D.; Yoshida, K.; Jensen, W. Relationship between grasping force and features of single-channel intramuscular EMG signals. J. Neurosci. Methods 2009, 185, 143-150. [CrossRef] 
35. De Almeida, P.H.T.Q.; da Cruz, D.M.C.; Magna, L.A.; Ferrigno, I.S.V. An electromyographic analysis of two handwriting grasp patterns. J. Electromyogr. Kinesiol. 2013, 23, 838-843. [CrossRef]

36. Maier, M.A.; Hepp-Reymond, M.-C. EMG activation patterns during force production in precision grip. Exp. Brain Res. 1995, 103, 108-122. [CrossRef]

37. Danion, F.; Galléa, C. The relation between force magnitude, force steadiness, and muscle co-contraction in the thumb during precision grip. Neurosci. Lett. 2004, 368, 176-180. [CrossRef] [PubMed]

38. Cooney, W.P.; An, K.-N.; Daube, J.R.; Askew, L.J. Electromyographic analysis of the thumb: A study of isometric forces in pinch and grasp. J. Hand Surg. Am. 1985, 10, 202-210. [CrossRef]

39. Kerkhof, F.D.; Deleu, G.; D'Agostino, P.; Vereecke, E.E. Subject-specific thumb muscle activity during functional tasks of daily life. J. Electromyogr. Kinesiol. 2016, 30, 131-136. [CrossRef] [PubMed]

40. Birdwell, J.A.; Hargrove, L.J.; Kuiken, T.A.; Weir, R.F. ff Activation of individual extrinsic thumb muscles and compartments of extrinsic finger muscles. J. Neurophysiol. 2013, 110, 1385-1392. [CrossRef]

41. Van Galen, G.P.; Müller, M.L.T.M.; Meulenbroek, R.G.J.; Van Gemmert, A.W.A. Forearm EMG response activity during motor performance in individuals prone to increased stress reactivity. Am. J. Ind. Med. 2002, 41, 406-419. [CrossRef]

42. Cifrek, M.; Medved, V.; Tonković, S.; Ostojić, S. Surface EMG Based Muscle Fatigue Evaluation in Biomechanics. Clin. Biomech. 2009, 24, 327-340. [CrossRef] [PubMed]

43. Taib, M.F.M.; Bahn, S.; Yun, M.H. The effect of psychosocial stress on muscle activity during computer work: Comparative study between desktop computer and mobile computing products. Work 2016, 54, 543-555. [CrossRef] [PubMed]

44. Straker, L.; Burgess-Limerick, R.; Pollock, C.; Maslen, B. The influence of desk and display design on posture and muscle activity variability whilst performing information technology tasks. Appl. Ergon. 2009, 40, 852-859. [CrossRef] [PubMed]

45. Kao, H.C.; Lin, C.J.; Lee, Y.H.; Chen, S.H. The Effects of Direction of Exertion, Path, and Load Placement in Nursing Cart Pushing and Pulling Tasks: An Electromyographical Study. PLoS ONE 2015, 10, e0140792. [CrossRef] [PubMed]

46. Di Domizio, J.; Keir, P.J. Forearm posture and grip effects during push and pull tasks. Ergonomics 2010, 53, 336-343. [CrossRef]

47. Hägg, G.M.; Milerad, E. Forearm extensor and flexor muscle exertion during simulated gripping work-An electromyographic study. Clin. Biomech. 1997, 12, 39-43. [CrossRef]

48. Sako, S.; Sugiura, H.; Tanoue, H.; Kojima, M.; Kono, M.; Inaba, R. Electromyographic analysis of relevant muscle groups during completion of computer tasks using different computer mouse positions. Int. J. Occup. Saf. Ergon. 2017, 23, 267-273. [CrossRef]

49. Szeto, G.P.Y.; Lin, J.K.M. A study of forearm muscle activity and wrist kinematics in symptomatic office workers performing mouse-clicking tasks with different precision and speed demands. J. Electromyogr. Kinesiol. 2011, 21, 59-66. [CrossRef]

50. Marta, S.; Silva, L.; Castro, M.A.; Pezarat-Correia, P.; Cabri, J. Electromyography variables during the golf swing: A literature review. J. Electromyogr. Kinesiol. 2012, 22, 803-813. [CrossRef]

51. Chow, J.W.; Carlton, L.G.; Lim, Y.T.; Shim, J.H.; Chae, W.S.; Kuenster, A.F. Muscle activation during the tennis volley. Med. Sci. Sports Exerc. 1999, 31, 846-854. [CrossRef] [PubMed]

52. Alizadehkhaiyat, O.; Frostick, S.P. Electromyographic assessment of forearm muscle function in tennis players with and without Lateral Epicondylitis. J. Electromyogr. Kinesiol. 2015, 25, 876-886. [CrossRef] [PubMed]

53. Hatch, G.F.; Pink, M.M.; Mohr, K.J.; Sethi, P.M.; Jobe, F.W. The effect of tennis racket grip size on forearm muscle firing patterns. Am. J. Sports Med. 2006, 34, 1977-1983. [CrossRef] [PubMed]

54. Rota, S.; Morel, B.; Saboul, D.; Rogowski, I.; Hautier, C. Influence of fatigue on upper limb muscle activity and performance in tennis. J. Electromyogr. Kinesiol. 2014, 24, 90-97. [CrossRef]

55. Sorbie, G.G.; Hunter, H.H.; Grace, F.M.; Gu, Y.; Baker, J.S.; Ugbolue, U.C. An electromyographic study of the effect of hand grip sizes on forearm muscle activity and golf performance. Res. Sport. Med. 2016, 24, 207-218. [CrossRef] [PubMed]

56. Santello, M.; Baud-Bovy, G.; Jörntell, H. Neural bases of hand synergies. Front. Comput. Neurosci. 2013, 7, 23. [CrossRef]

57. Santello, M.; Flanders, M.; Soechting, J.F. Postural hand synergies for tool use. J. Neurosci. 1998, 18, 10105-10115. [CrossRef] [PubMed]

58. Gracia-Ibáñez, V.; Sancho-Bru, J.L.; Vergara, M.; Jarque-Bou, N.J.; Roda-Sales, A. Sharing of hand kinematic synergies across subjects in daily living activities. Sci. Rep. 2020. [CrossRef]

59. Jarrassé, N.; Ribeiro, A.T.; Sahbani, A.; Bachta, W.; Roby-Brami, A. Analysis of hand synergies in healthy subjects during bimanual manipulation of various objects. J. Neuroeng. Rehabil. 2014. [CrossRef]

60. Weiss, E.J.; Flanders, M. Muscular and Postural Synergies of the Human Hand. J. Neurophysiol. 2004, 92, 523-535. [CrossRef] [PubMed]

61. Zariffa, J.; Steeves, J.; Pai, D.K. Changes in hand muscle synergies in subjects with spinal cord injury: Characterization and functional implications. J. Spinal Cord Med. 2012, 35, 310-318. [CrossRef] [PubMed]

62. Scano, A.; Chiavenna, A.; Molinari Tosatti, L.; Müller, H.; Atzori, M. Muscle Synergy Analysis of a Hand-Grasp Dataset: A Limited Subset of Motor Modules May Underlie a Large Variety of Grasps. Front. Neurorobot. 2018, 12, 57. [CrossRef] [PubMed]

63. Winges, S.A.; Furuya, S.; Faber, N.J.; Flanders, M. Patterns of muscle activity for digital coarticulation. J. Neurophysiol. 2013, 110, 230-242. [CrossRef]

64. D'Andola, M.; Cesqui, B.; Portone, A.; Fernandez, L.; Lacquaniti, F.; d'Avella, A. Spatiotemporal characteristics of muscle patterns for ball catching. Front. Comput. Neurosci. 2013, 7, 107. [CrossRef] 
65. Ertan, H.; Kentel, B.; Tümer, S.T.; Korkusuz, F. Activation patterns in forearm muscles during archery shooting. Hum. Mov. Sci. 2003, 22, 37-45. [CrossRef]

66. VencesBrito, A.M.; Rodrigues Ferreira, M.A.; Cortes, N.; Fernandes, O.; Pezarat-Correia, P. Kinematic and electromyographic analyses of a karate punch. J. Electromyogr. Kinesiol. 2011, 21, 1023-1029. [CrossRef] [PubMed]

67. Ertan, H. Muscular activation patterns of the bow arm in recurve archery. J. Sci. Med. Sport 2009, 12, 357-360. [CrossRef]

68. Ricci, F.P.F.M.; Santiago, P.R.P.; Zampar, A.C.; Pinola, L.N.; de Fonseca, M.C.R. Upper extremity coordination strategies depending on task demand during a basic daily activity. Gait Posture 2015, 42, 472-478. [CrossRef] [PubMed]

69. Geethanjali, P. Myoelectric control of prosthetic hands: State-of-the-art review. Med. Devices Evid. Res. 2016, 9, 247-255. [CrossRef]

70. Johnson, S.S.; Mansfield, E. Prosthetic training: Upper limb. Phys. Med. Rehabil. Clin. N. Am. 2014, 25, 133-151. [CrossRef] [PubMed]

71. Kaufman, K.R.; An, K.N.; Litchy, W.J.; Cooney, W.P.; Chao, E.Y. In-vivo function of the thumb muscles. Clin. Biomech. 1999, 14, 141-150. [CrossRef]

72. Disselhorst-Klug, C.; Schmitz-Rode, T.; Rau, G. Surface electromyography and muscle force: Limits in sEMG-force relationship and new approaches for applications. Clin. Biomech. 2009, 24, 225-235. [CrossRef]

73. Jarque-Bou, N.J.; Vergara, M.; Sancho-Bru, J.L.; Roda-Sales, A.; Gracia-Ibáñez, V. Identification of forearm skin zones with similar muscle activation patterns during activities of daily living. J. Neuroeng. Rehabil. 2018, 15. [CrossRef]

74. Jakobi, J.M.; Edwards, D.L.; Connelly, D.M. Utility of Portable Electromyography for Quantifying Muscle Activity during Daily Use. Gerontology 2008, 54, 324-331. [CrossRef] [PubMed]

75. Peters, K.M.; Kelly, V.E.; Chang, T.; Weismann, M.C.; Westcott McCoy, S.; Steele, K.M. Muscle recruitment and coordination during upper-extremity functional tests. J. Electromyogr. Kinesiol. 2018, 38, 143-150. [CrossRef] [PubMed]

76. Kern, D.S.; Semmler, J.G.; Enoka, R.M. Long-term activity in upper- and lower-limb muscles of humans. J. Appl. Physiol. 2001, 91, 2224-2232. [CrossRef]

77. Jebsen, R.H.; Taylor, N.; Trieschmann, R.B.; Trotter, M.J.; Howard, L.A. An objective and standardized test of hand function. Arch. Phys. Med. Rehabil. 1969, 50, 311-319.

78. Barreca, S.; Kelly Gowland, C.; Stratford, P.; Huijbregts, M.; Griffiths, J.; Torresin, W.; Dunkley, M.; Miller, P.; Masters, L. Development of the Chedoke Arm and Hand Activity Inventory: Theoretical Constructs, Item Generation, and Selection. Top. Stroke Rehabil. 2004, 11, 31-42. [CrossRef]

79. Brogardh, C.; Persson, A.L.; Sjolund, B.H. Intra- and inter-rater reliability of the Sollerman hand function test in patients with chronic stroke. Disabil. Rehabil. 2007, 29, 145-154. [CrossRef] [PubMed]

80. Kilbreath, S.L.; Gandevia, S.C. Limited independent flexion of the thumb and fingers in human subjects. J. Physiol. 1994, 479 Pt 3, 487-497. [CrossRef]

81. Jarque-Bou, N.J.; Vergara, M.; Sancho-Bru, J.L.; Gracia-Ibáñez, V.; Roda-Sales, A. A calibrated database of kinematics and EMG of the forearm and hand during activities of daily living. Sci. Data 2019, 6, 270. [CrossRef] [PubMed]

82. Tresch, M.C.; Jarc, A. The case for and against muscle synergies. Curr. Opin. Neurobiol. 2009, 19, 601-607. [CrossRef]

83. Schieber, M.H.; Lang, C.E.; Reilly, K.T.; McNulty, P.; Sirigu, A. Selective activation of human finger muscles after stroke or amputation. Adv. Exp. Med. Biol. 2009, 629, 559-575. [CrossRef] [PubMed]

84. Kutch, J.J.; Kuo, A.D.; Bloch, A.M.; Rymer, W.Z. Endpoint force fluctuations reveal flexible rather than synergistic patterns of muscle cooperation. J. Neurophysiol. 2008, 100, 2455-2471. [CrossRef] [PubMed]

85. Valero-Cuevas, F.J.; Venkadesan, M.; Todorov, E. Structured variability of muscle activations supports the minimal intervention principle of motor control. J. Neurophysiol. 2009, 102, 59-68. [CrossRef] [PubMed]

86. Jo, H.J.; Maenza, C.; Good, D.C.; Huang, X.; Park, J.; Sainburg, R.L.; Latash, M.L. Effects of unilateral stroke on multi-finger synergies and their feed-forward adjustments. Neuroscience 2016, 319, 194-205. [CrossRef] [PubMed]

87. Valero-Cuevas, F.J.; ZAJAC, F.E.; Burgar, C.G. Large index-fingertip forces are produced by subject-independent patterns of muscle excitation. J. Biomech. 1998, 31, 693-703. [CrossRef]

88. Valero-Cuevas, F.J. Predictive modulation of muscle coordination pattern magnitude scales fingertip force magnitude over the voluntary range. J. Neurophysiol. 2000, 83, 1469-1479. [CrossRef]

89. Johnston, J.A.; Winges, S.A.; Santello, M. Neural control of hand muscles during prehension. Adv. Exp. Med. Biol. 2009, 629, 577-596.

90. Gribble, P.L.; Mullin, L.I.; Cothros, N.; Mattar, A. Role of Cocontraction in Arm Movement Accuracy. J. Neurophysiol. 2003, 89, 2396-2405. [CrossRef]

91. Milner, T.E.; Cloutier, C. Compensation for mechanically unstable loading in voluntary wrist movement. Exp. Brain Res. 1993, 94, 522-532. [CrossRef]

92. D'Avella, A.; Fernandez, L.; Portone, A.; Lacquaniti, F. Modulation of phasic and tonic muscle synergies with reaching direction and speed. J. Neurophysiol. 2008, 100, 1433-1454. [CrossRef] [PubMed]

93. d'Avella, A.; Lacquaniti, F. Control of reaching movements by muscle synergy combinations. Front. Comput. Neurosci. 2013, 7, 42. [CrossRef] [PubMed]

94. Smeets, J.B.J.; Brenner, E. Synergies in Grasping. In Advances in Experimental Medicine and Biology; Springer: Cham, Switzerland, 2016; Volume 957, pp. 21-34. 
95. Klein Breteler, M.D.; Simura, K.J.; Flanders, M. Timing of muscle activation in a hand movement sequence. Cereb. Cortex 2007, 17, 803-815. [CrossRef] [PubMed]

96. Martelloni, C.; Carpaneto, J.; Micera, S. Characterization of EMG patterns from proximal arm muscles during object- and orientation-specific grasps. IEEE Trans. Biomed. Eng. 2009, 56, 2529-2536. [CrossRef] [PubMed]

97. Rabbi, M.F.; Pizzolato, C.; Lloyd, D.G.; Carty, C.P.; Devaprakash, D.; Diamond, L.E. Non-negative matrix factorisation is the most appropriate method for extraction of muscle synergies in walking and running. Sci. Rep. 2020. [CrossRef]

98. Ebied, A.; Kinney-Lang, E.; Spyrou, L.; Escudero, J. Evaluation of matrix factorisation approaches for muscle synergy extraction. Med. Eng. Phys. 2018. [CrossRef] [PubMed]

99. Castellini, C.; Van Der Smagt, P. Evidence of muscle synergies during human grasping. Biol. Cybern. 2013, 107, 233-245. [CrossRef]

100. Burkhart, T.A.; Andrews, D.M. Kinematics, kinetics and muscle activation patterns of the upper extremity during simulated forward falls. J. Electromyogr. Kinesiol. 2013, 23, 688-695. [CrossRef]

101. d'Avella, A.; Saltiel, P.; Bizzi, E. Combinations of muscle synergies in the construction of a natural motor behavior. Nat. Neurosci. 2003, 6, 300-308. [CrossRef]

102. Gazzoni, M.; Celadon, N.; Mastrapasqua, D.; Paleari, M.; Margaria, V.; Ariano, P. Quantifying forearm muscle activity during wrist and finger movements by means of multi-channel electromyography. PLoS ONE 2014, 9, e109943. [CrossRef]

103. Hu, X.; Suresh, N.L.; Xue, C.; Rymer, W.Z. Extracting extensor digitorum communis activation patterns using high-density surface electromyography. Front. Physiol. 2015, 6. [CrossRef]

104. Tanzarella, S.; Muceli, S.; Del Vecchio, A.; Casolo, A.; Farina, D. Non-invasive analysis of motor neurons controlling the intrinsic and extrinsic muscles of the hand. J. Neural Eng. 2020. [CrossRef]

105. Hagert, E. Proprioception of the Wrist Joint: A Review of Current Concepts and Possible Implications on the Rehabilitation of the Wrist. J. Hand Ther. 2010, 23, 2-17. [CrossRef] [PubMed]

106. Hsiao, L.-P.; Cho, C.-Y. The effect of aging on muscle activation and postural control pattern for young and older computer users. Appl. Ergon. 2012, 43, 926-932. [CrossRef]

107. Cheung, V.C.K.; Turolla, A.; Agostini, M.; Silvoni, S.; Bennis, C.; Kasi, P.; Paganoni, S.; Bonato, P.; Bizzi, E. Muscle synergy patterns as physiological markers of motor cortical damage. Proc. Natl. Acad. Sci. USA 2012, 109, 14652-14656. [CrossRef]

108. Roh, J.; Rymer, W.Z.; Beer, R.F. Evidence for altered upper extremity muscle synergies in chronic stroke survivors with mild and moderate impairment. Front. Hum. Neurosci. 2015, 9, 1-14. [CrossRef] [PubMed]

109. Lee, S.W.; Triandafilou, K.; Lock, B.A.; Kamper, D.G. Impairment in task-specific modulation of muscle coordination correlates with the severity of hand impairment following stroke. PLoS ONE 2013, 8, e68745. [CrossRef]

110. Hesam-Shariati, N.; Trinh, T.; Thompson-Butel, A.G.; Shiner, C.T.; McNulty, P.A. A Longitudinal Electromyography Study of Complex Movements in Poststroke Therapy. 1: Heterogeneous Changes Despite Consistent Improvements in Clinical Assessments. Front. Neurol. 2017, 8, 340. [CrossRef] [PubMed]

111. Lunardini, F.; Casellato, C.; Bertucco, M.; Sanger, T.D.; Pedrocchi, A. Children With and Without Dystonia Share Common Muscle Synergies While Performing Writing Tasks. Ann. Biomed. Eng. 2017, 45, 1949-1962. [CrossRef] [PubMed]

112. Pellegrino, L.; Coscia, M.; Muller, M.; Solaro, C.; Casadio, M. Evaluating upper limb impairments in multiple sclerosis by exposure to different mechanical environments. Sci. Rep. 2018, 8, 2110. [CrossRef]

113. Safavynia, S.A.; Torres-Oviedo, G.; Ting, L.H. Muscle Synergies: Implications for Clinical Evaluation and Rehabilitation of Movement. Top. Spinal Cord Inj. Rehabil. 2011, 17, 16-24. [CrossRef] [PubMed]

114. Hebert, J.S.; Lewicke, J.; Williams, T.R.; Vette, A.H. Normative data for modified Box and Blocks test measuring upper-limb function via motion capture. J. Rehabil. Res. Dev. 2014, 51, 918-932. [CrossRef] [PubMed] 